OPEN ACCESS

Edited by:

Loretta Tuosto,

Sapienza University, Italy

Reviewed by:

Linda M. Bradley,

Sanford-Burnham Institute

for Medical Research, USA

Min-Ho Kim,

Kent State University, USA

*Correspondence:

Jasmeen S. Merzaban

jasmeen.merzaban@kaust.edu.sa

Specialty section:

This article was submitted

to T Cell Biology,

a section of the journal

Frontiers in Immunology

Received: 05 December 2016 Accepted: 10 April 2017

Published: 03 May 2017

Citation:

Ali AJ, Abuelela AF and Merzaban JS (2017) An Analysis of Trafficking Receptors Shows that CD44 and P-Selectin Glycoprotein Ligand-1 Collectively Control the Migration of Activated Human T-Cells.

Front. Immunol. 8:492. doi: 10.3389/fimmu.2017.00492

\section{An Analysis of Trafficking Receptors Shows that CD44 and P-Selectin Glycoprotein Ligand-1 Collectively Control the Migration of Activated Human T-Cells}

\author{
Amal J. Ali, Ayman F. Abuelela and Jasmeen S. Merzaban*
}

King Abdullah University of Science and Technology (KAUST), Division of Biological and Environmental Sciences and Engineering (BESE), Thuwal, Saudi Arabia

Selectins guide the traffic of activated T-cells through the blood stream by mediating their tethering and rolling onto inflamed endothelium, in this way acting as beacons to help navigate them to sites of inflammation. Here, we present a comprehensive analysis of E-selectin ligands expressed on activated human T-cells. We identified several novel glycoproteins that function as E-selectin ligands. Specifically, we compared the role of P-selectin glycoprotein ligand-1 (PSGL-1) and CD43, known E-selectin ligands, to CD44, a ligand that has not previously been characterized as an E-selectin ligand on activated human T-cells. We showed that CD44 acts as a functional E-selectin ligand when expressed on both $\mathrm{CD} 4^{+}$and $\mathrm{CD} 8^{+} \mathrm{T}$-cells. Moreover, the CD44 protein carries a binding epitope identifying it as hematopoietic cell E- and/or L-selectin ligand (HCELL). Furthermore, by knocking down these ligands individually or together in primary activated human T-cells, we demonstrated that CD44/HCELL, and not CD43, cooperates with PSGL-1 as a major E-selectin ligand. Additionally, we demonstrated the relevance of our findings to chronic autoimmune disease, by showing that CD44/HCELL and PSGL-1, but not CD43, from T-cells isolated from psoriasis patients, bind E-selectin.

Keywords: E-selectin, CD44, hematopoietic cell E- and/or L-selectin ligand, P-selectin glycoprotein ligand-1 (CD162), cell adhesion, cell migration, human activated T-cells, psoriasis

\section{INTRODUCTION}

Recruitment and infiltration of T-cells are necessary for the development and maintenance of the immune response. Immune dysregulation occurs when the natural response to protect against pathogens and injuries is disrupted, a state that can lead to autoimmunity. Psoriasis, characterized by painful red skin lesions, is an autoimmune skin disease that affects about $2-5 \%$ of the world population $(1,2)$. Activated T-cells are key players in mediating the immune response causing skin diseases, such as psoriasis $(3,4)$, likely explained by their tendency to upregulate functional selectin ligands and chemokines that are associated with their migration to skin $(5,6)$. This migration requires that

Abbreviations: E-Ig, recombinant E-selectin-Ig chimera; HA, hyaluronic acid; HSPCs, hematopoietic stem/progenitor cells; HCELL, hematopoietic cell E- and/or L-selectin ligand; mAbs, monoclonal antibodies; PSGL-1, P-selectin glycoprotein ligand-1; siRNA, small interfering RNA; sLex/a, sialyl Lewis x/a. 
activated T-cells tether and roll onto selectins expressed on the endothelium ultimately leading to transendothelial migration following a period of arrest (6-8). Tethering and rolling are highly dependent on the ability of activated T-cells to express glycoproteins that reversibly and transiently bind to P- and E-selectins (9-11). In mice, both selectins have overlapping and partially redundant functions $(12,13)$. In human, however, P-selectin is only minimally expressed at sites of leukocyte infiltration, such as at dermal venules, and where hematopoietic stem/progenitor cells (HSPCs) infiltrate at bone marrow sinusoids $(14,15)$. Moreover, the ability of some inflammatory mediators, such as tumor necrosis factor and lipopolysaccharides, to induce the expression of human E-selectin, but not P-selectin, limits the relevance of P-selectin-mediated skin inflammatory responses in humans (11, 15-17).

To date, only two E-selectin ligands have been reported on activated human T-cells: P-selectin glycoprotein ligand-1 (PSGL-1; CD162) (18) and $\operatorname{CD} 43(19,20)$. In mice, in vivo studies have illustrated that a concomitant deficiency of these ligands is not sufficient to completely eliminate E-selectin-dependent migration of activated T-cells, suggesting other ligands are present $(20,21)$. In this study, we utilized the power of mass spectrometry to identify unknown E-selectin ligands expressed on the surface of activated human T-cells. Using this technology, we detected a repertoire of glycoproteins that bind to recombinant E-selectin protein. In addition to the previously described ligands, PSGL-1 and CD43, we also identified CD44 on activated human T-cells. CD44 is a structurally variable cell surface glycoprotein that ranges in size from 85 to $250 \mathrm{kDa}$. This variability is mediated by alternative splicing as well as extensive posttranslational modifications including $N$ - and $O$-glycosylation and glycosaminoglycan attachment (22). The most abundant form of CD44 is the standard form (CD44s; 85-95 kDa), which lacks the variable exons (v2-v10 and exon 18) (23), and it is mostly $N$-glycosylated (24). CD44s is also designated as $\mathrm{CD} 44 \mathrm{H}$ because it is expressed mainly on cells of lympho-hematopoietic origin (25). CD44 marks activated and memory T-cells and is reported to function as an E-selectin ligand on HSPCs, neutrophils, and mouse T helper-1 cells (26-29). Furthermore, binding of CD44 to hyaluronic acid (HA) increases both T-cell proliferation and extravasation into inflammatory sites $(30,31)$; however, its role as an E-selectin ligand on human T-cells has not previously been established. In fact, it is reported that CD44 from CLA ${ }^{+}$human T-cells does not interact with E-selectin (19). Although CD44 was reported as an E-selectin ligand on mouse T helper-1 cells, extrapolating studies from mouse to humans should be done with caution due to the significant differences between the human and mouse immune systems $(29,32,33)$. Therefore, we found it crucial to explore the role of CD44 as a functional E-selectin ligand on human activated T-cells. Here, we demonstrated that CD44 isolated from human activated $\mathrm{CD}^{+}$and $\mathrm{CD}^{+}$T-cells is decorated with sialofucosylated glycans and binds to E-selectin, which thereby defines it as the specialized glycoform, hematopoietic cell E- and/or L-selectin ligand (HCELL) $(26,34)$. Moreover, in vivo-activated T-cells isolated from psoriasis patients strongly suggest that both PSGL-1 and CD44, but not CD43, are the major E-selectin ligands. Using a small interfering RNA (siRNA) knockdown approach in primary activated human T-cells, we demonstrated that CD44 cooperates with PSGL-1 to maintain and support T-cell rolling under physiological flow conditions. This work has significant implications in the development of targeted therapies to combat inflammatory diseases where T-cell trafficking is more dependent on E-selectin expression (i.e., psoriasis, rheumatoid arthritis) to selectively interfere with the pathophysiology of these diseases through the targeting of a subset of these major E-selectin ligands.

\section{RESULTS}

\section{CD44 Is an E-Selectin Ligand on Human Activated T-Cells}

Activation of naive human T-cells results in the expression of selectin ligands $(35,36)$. Selectins bind to specialized sialofucosylated carbohydrate determinants, prototypically displayed as the terminal tetrasaccharide sialyl Lewis structures (sLe ${ }^{\mathrm{x}}$; and/or to its isomer sLe $\left.{ }^{a}\right)(34,37)$. Flow cytometric analysis of sialyl Lewis $\mathrm{x} / \mathrm{a}$ expression on human activated T-cells was confirmed using specific monoclonal antibodies (mAbs), HECA-452 and CD15s $(18,27)$, that were shown to markedly increase after activation subsequently leading to E-selectin binding [E-selectin-hIg chimera (E-Ig); Figure 1A]. Overall, these results suggest that human T-cells were appropriately stimulated in culture to express functional E-selectin ligands.

In order to fully elucidate the potential repertoire of E-selectin ligands on the surface of activated human T-cells, we immunopurified the ligands using E-Ig and the products were analyzed by mass spectrometry; of the 32 proteins detected (Table S1 in Supplementary Material), 10 were identified as cell membrane glycoproteins that could bind E-selectin (Table 1). The role of CD44 in many cellular processes, including growth, survival, differentiation, and migration of hematopoietic cells (18, 27, $34,38,39)$, motivated us to substantiate its involvement in E-selectin-mediated T-cell migration. To this end, we immunopurified equal amounts of CD44 from naïve and activated T-cells (Figure 1B) and assessed E-Ig-binding activity by Western blot. As illustrated in Figure 1B (left), the CD44 isolated from naïve $\mathrm{T}$ cells is non-functional and gained E-selectin binding activity only upon T-cell activation. To identify the T-cell subset that expressed E-selectin binding activity toward CD44, we purified CD4 and CD8 cells from the activated T-cell pool with more than $90 \%$ purity (Figure S1 in Supplementary Material) and subsequently immuno-purified CD44 from each population; CD44 from both subsets showed E-selectin binding (Figure 1B, right). Moreover, T-cell phenotyping of the $\mathrm{CD}^{+}{ }^{+}$subset identified them as mainly of Th2 phenotype (Table S2 in Supplementary Material). HCELL is recognized as a sialofucosylated glycoform of CD44, originally found on HSPCs, that acts as an E-selectin and/or L-selectin ligand $(26,34)$. Our analysis shows that CD44 from activated human T-cells bind exclusively to E-selectin and not to L- or P-selectin (Figure S2 in Supplementary Material). In the work outlined here, CD44 will be considered as HCELL (and designated CD44/HCELL) since it stains positive for sialofucosylated glycans, albeit weaker than PSGL-1 (Figure S3 in Supplementary Material), and binds E-selectin. 

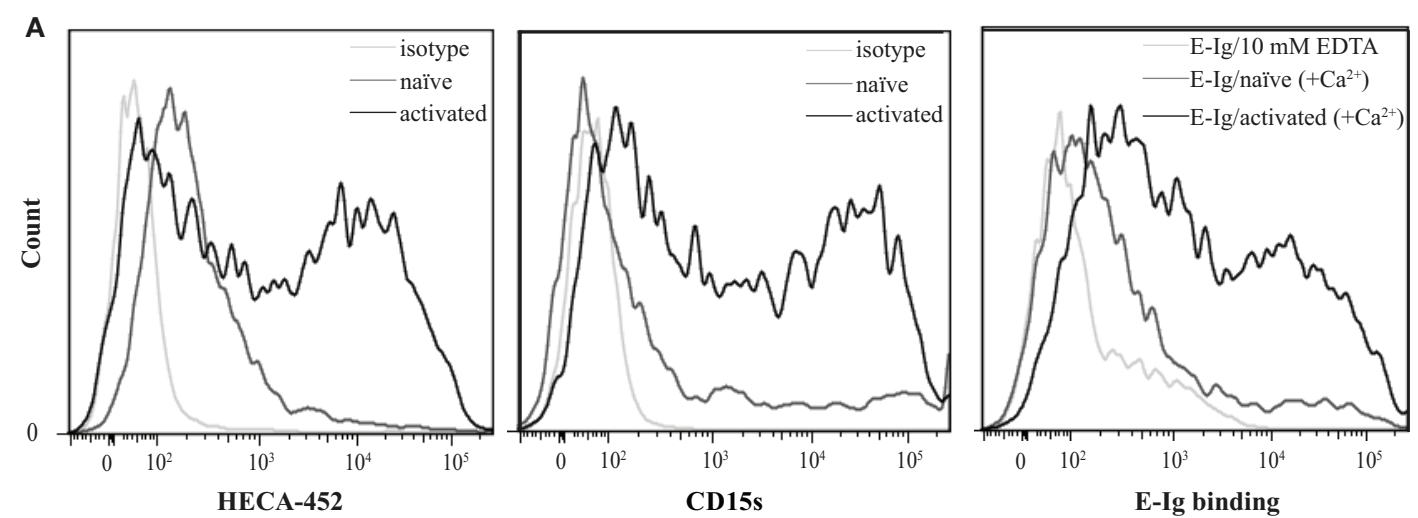

B

CD44 IP

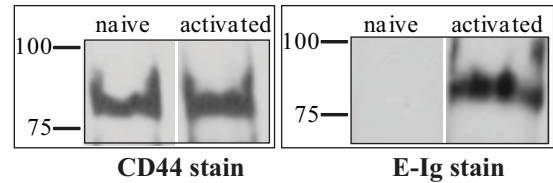

CD44 IP

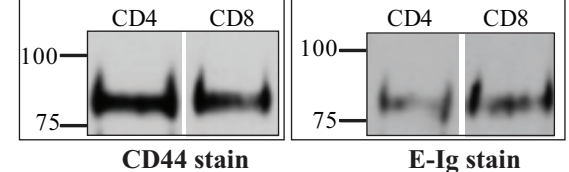

C

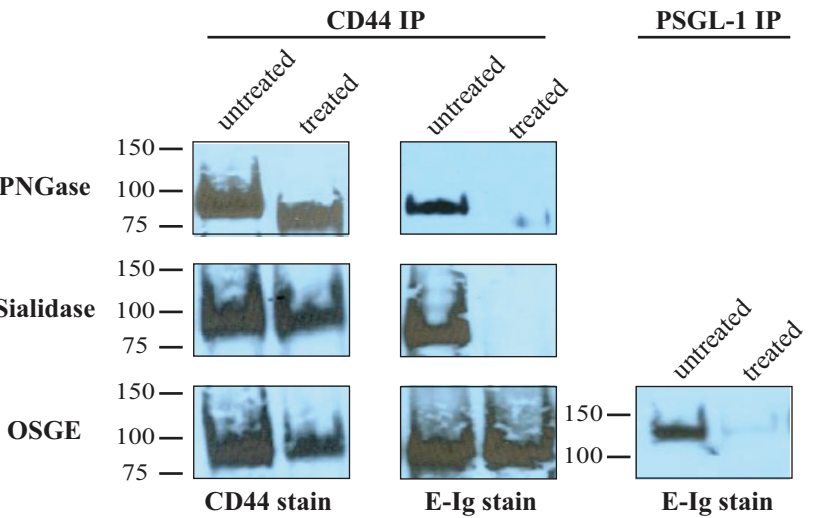

FIGURE 1 | CD44/HCELL isolated from activated human T-cells serves as an E-selectin ligand. (A) sLe $e^{\mathrm{x}}$ expression was assayed by the reactivity of activated (black) and naïve (dark-gray) T-cells to HECA-452 (left panel) or CD15s (middle panel) monoclonal antibodies. The isotype controls were included as negative controls (light-gray). E-lg binding to activated (black) versus naïve (dark-gray) human T-cells (right panel) is shown in the right panel. To assay for nonspecific interactions, 10-mM EDTA (light-gray) was added to the assay buffer. These are representative flow cytometric histograms of $n=3$ independent experiments. (B) CD44 was immuno-purified from naïve and activated T-cells (right panel) and from activated human CD4+ and CD8 ${ }^{+}$T-cells (left panel) purified using autoMACS (Figure S1 in Supplementary Material). The samples were prepared for Western blot analysis and stained with either CD44 or E-lg (or secondary alone controls; Figure S4 in Supplementary Material). E-Ig specifically binds to CD44 immuno-purified from both activated CD4+ and CD8 ${ }^{+}$T-cells but not naïve T-cells. These are representative blots of $n=3$ independent experiments. (C) CD44 was immuno-purified from activated T-cells that were either untreated or treated with PNGaseF to remove N-glycans (upper panels), sialidase to remove sialic acid (middle panels), or OSGE to remove O-glycans (lower panels) and prepared for Western blot analysis for CD44 expression or for binding to E-lg. Note that the data suggest that the interaction between E-selectin and CD44 is N-glycan and sialic acid dependent but that it is not affected by the removal of O-glycans. The efficiency of OSGE enzymatic treatment was confirmed by its ability to abolish the E-selectin binding capacity of P-selectin glycoprotein ligand-1 (PSGL-1) after the removal of O-glycan. These are representative blots of $n=3$ independent experiments.

To characterize the contribution of glycans (38) to E-selectin binding on CD44/HCELL, immuno-purified CD44 was treated with enzymes to remove $\mathrm{N}$ - or $\mathrm{O}$-glycans (PNGaseF or OSGE, respectively) prior to Western blot analysis for E-selectin binding (with E-Ig). As evident in Figure 1C, the E-selectin interaction with CD44/HCELL was abolished when $N$-glycans were removed (Figure 1C, top) but not when $O$-glycans were removed (Figure 1C, bottom). CD44/HCELL treated with
PNGaseF displayed altered mobility on SDS-PAGE confirming the efficacy of the treatment (Figure 1C). As CD44/HCELL is not highly $O$-glycosylated, we did not detect a change in mobility following OSGE treatment but to confirm the efficacy of removal of $O$-glycans, we illustrated that PSGL-1 binding to E-selectin was abolished (Figure 1C) since this interaction is $O$-glycan dependent. Finally, treatment with sialidase to remove the sialic acid completely abolished the interaction of E-selectin with 
TABLE 1 | E-selectin ligands were immuno-purified from activated human T-cell lysate and the purified proteins were subjected to mass spectrometry analysis for ligand identification.

\section{Protein name}

Leukosialin (CD43)

$\mathrm{P}$-selectin glycoprotein ligand-1

CD44 antigen

T-cell differentiation antigen CD6

Facilitated glucose transporter member 1

Dipeptidyl peptidase 4

Facilitated glucose transporter member 3

Transferrin receptor protein 1

4F2 cell surface antigen heavy chain

HLA class I histocompatibility antigen, Cw-12 alpha chain
Peptide sequence

NGWDAWAGPAQVPEEGAVTVTVGGSGGDKGSGFPDGEGSSR/QGSLAMEELK/TGALVLSR SPGLTPEPR

ESSETPDQFMTADETR/LVINSGNGAVEDR/NLQNVDMK

HRVTDEEVQQSR/VTDEEVQQSR

GTADVTHDLQEMKEESR/QGGASQSDKTPEELFHPLGADSQV/TFDEIASGFR

LGTFEVEDQIEAAR/VLEDNSALDK

AFEGQAHGADR/LWGTQDVSQDIQEMKDESAR

LAVDEEENADNNTK/LLNENSYVPR/SSGLPNIPVQTISR

ADLLLSTQPGREEGSPLELER/IKVAEDEAEAAAAAKNAEDEAEAAAAAK

DGEDQTQDTELVETRPAGDGTFQK/FDSDAASPR/WAAWVPSGEEQR/FIAVGYVDDTQFVR

Lists all the identified membrane glycoproteins along with their corresponding identified peptide sequence(s).

CD44/HCELL (Figure 1C, middle). These experiments demonstrated that E-selectin recognizes $N$-linked sialylated glycans on CD44/HCELL of activated human T-cells much similar to that of HSPCs $(26,27,34,40)$.

Recent studies have underscored the importance of the CD44 variant $(\mathrm{CD} 44 \mathrm{v})$ isoforms in mediating E-selectin binding of a number of cancer cell lines $(24,41)$. Therefore, we sought to investigate whether CD44s and/or CD44v are involved in E-selectin-binding activity on activated human T-cells. To determine which isoform is expressed on activated human T-cells, we initially screened naïve and activated T-cells for CD44 expression using either anti-CD44 mAbs that recognize both the standard and variant CD44 isoforms (clones 515 and 2C5) or that are specific for each of the variant isoforms alone. Our flow cytometric analysis illustrated that the majority of CD44 expressed on naïve T-cells is of the CD44s isoform and a small amount is of the CD44v10 isoform (Figure 2A, left panel). Following activation, the majority of CD44 remains of the CD44s isoform with a small population of cells that express the CD44v6 isoform (i.e., no CD44v3-5/7-9 is detected) (Figure 2A, right panel). A time course analysis of activated cells showed that the expression of the CD44v6 peaked at 24-48 $\mathrm{h}$ after activation and decreased at Day 5. To determine whether CD44v6 or CD44s possessed E-selectin ligand activity, we serially immuno-purified CD44v6 (Figure 2B, left panel), CD44v10, and finally CD44s (Figure 2B, right panel) from the same lysate at different time points after activation (24 h, $48 \mathrm{~h}$, and Day 5), and then we conducted a Western blot analysis. Figure 2B shows that the anti-CD44v6 $\mathrm{mAb}$ immuno-purified a protein that expresses exon 6 (stained with CD44v6 mAb) and exon 10 (stained with CD44v10 mAb) from activated T-cell lysates, which implies that the transcript(s) that express CD44v6 also harbor CD44v10 (Figure 2B, left panel). Interestingly, the expression of CD44s increases with time from $24 \mathrm{~h}$ to Day 5 of the culture (Figure 2B, right panel). E-selectin binding studies show that CD44s, but not CD44v6/10, bind to E-selectin and that the binding was time dependent starting at $48 \mathrm{~h}$ increasing dramatically by Day 5 of the culture (Figure 2C).

To determine if CD44/HCELL supports E-selectin binding under physiological flow, we used the blot rolling assay, which allowed us to compare the ability of immuno-purified CD44/ HCELL and PSGL-1 (positive control) isolated from the same activated T-cell lysate to support the rolling of CHO-E cells under defined shear flow conditions. As illustrated in Figure 3A
(Videos S1 and S2 in Supplementary Material), CHO-E cells specifically interacted with CD44/HCELL and PSGL-1 and this binding was $\mathrm{Ca}^{2+}$ dependent as it was lost when cells were suspended in 5-mM EDTA buffer. The average velocities of the cells rolling over CD44/HCELL and PSGL-1 in five fields/ligands were comparable $\left(3.3 \pm 0.1 \mu \mathrm{M} \mathrm{s}^{-1}\right.$ for CD44 and $2.6 \pm 0.1 \mu \mathrm{M} \mathrm{s}^{-1}$ for PSGL-1, Figure 3A). Thus, CD44/HCELL displayed $\mathrm{Ca}^{2+}$ dependent E-selectin ligand activity under flow conditions comparable to PSGL-1.

Next, we used a recently developed novel and robust realtime immunoprecipitation assay (40) to perform a comparative analysis for measuring the interaction of native ligands expressed on human activated T-cells with E-Ig. Both CD44 and PSGL-1 from activated T-cell lysates were captured on a BIAcore CM5 chip by using mAbs Hermes- 3 and KPL-1, respectively. To study the ability of immobilized CD44/Hermes-3-mAb and PSGL-1/ KPL-1-mAb complexes to interact with E-Ig, we injected 100-nM E-Ig in the presence of 5-mM EDTA or $1-\mathrm{mM} \mathrm{Ca}^{2+}$ at $50-\mathrm{mM}$ $\mathrm{NaCl}$. The accumulated number of E-Ig response units on the complexes during both E-Ig injection and buffer washing was measured and subtracted from the non-specific interaction with the isotype controls. Our data show that both proteins are able to bind E-Ig. Again, the specificity of the interaction was confirmed by the loss of binding when EDTA was added (Figure 3B, upper panels).

We next aimed to measure and compare the affinity and kinetics of CD44/HCELL and PSGL-1 to bind E-Ig. To achieve this, we used the steady-state model to determine the $K_{\mathrm{D}}$, which required injection of serial dilutions of E-Ig over the stably immobilized CD44/HCELL and PSGL-1 ligands. These studies were performed in buffers containing $150-\mathrm{mM} \mathrm{NaCl}$ to resemble the salt concentration in the circulation. As illustrated in Figure 3B (lower panels), E-Ig interacted with its ligands in a dose-dependent manner and we determined the $K_{\mathrm{D}}$ for E-Ig binding to CD44/HCELL $(777 \pm 40 \mathrm{nM})$ and PSGL-1 $(467 \pm 95 \mathrm{nM})$ to be comparable. Following the final E-Ig injection and during the buffer washing step, we determined the apparent dissociation rate constant $\left(k_{\text {off-apparent }}\right)$ to be $4.9 \times 10^{-5} \pm 2.1 \times 10^{-5} \mathrm{~s}^{-1}$ for CD44/HCELL and $25 \times 10^{-6} \pm 4.7 \times 10^{-6} \mathrm{~s}^{-1}$ for PSGL-1 (Figure 3B, lower panels). Thus, using Eq. 1 in Supplementary Material, the estimated apparent association rate constant $\left(k_{\text {on-apparent }}\right)$ was $61 \pm 24 \mathrm{M}^{-1} \mathrm{~s}^{-1}$ for CD44/HCELL and $52 \pm 5.5 \mathrm{M}^{-1} \mathrm{~s}^{-1}$ for PSGL-1 suggesting no statistically significant difference between the dissociation rate 


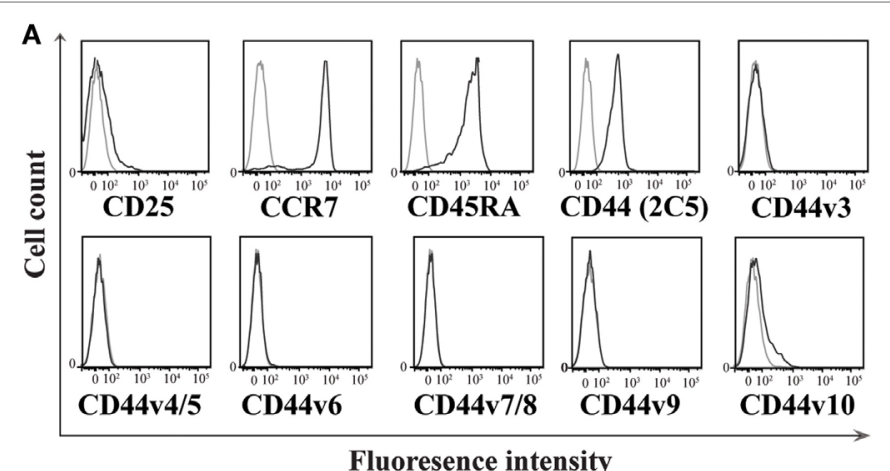

Fluoresence intensity
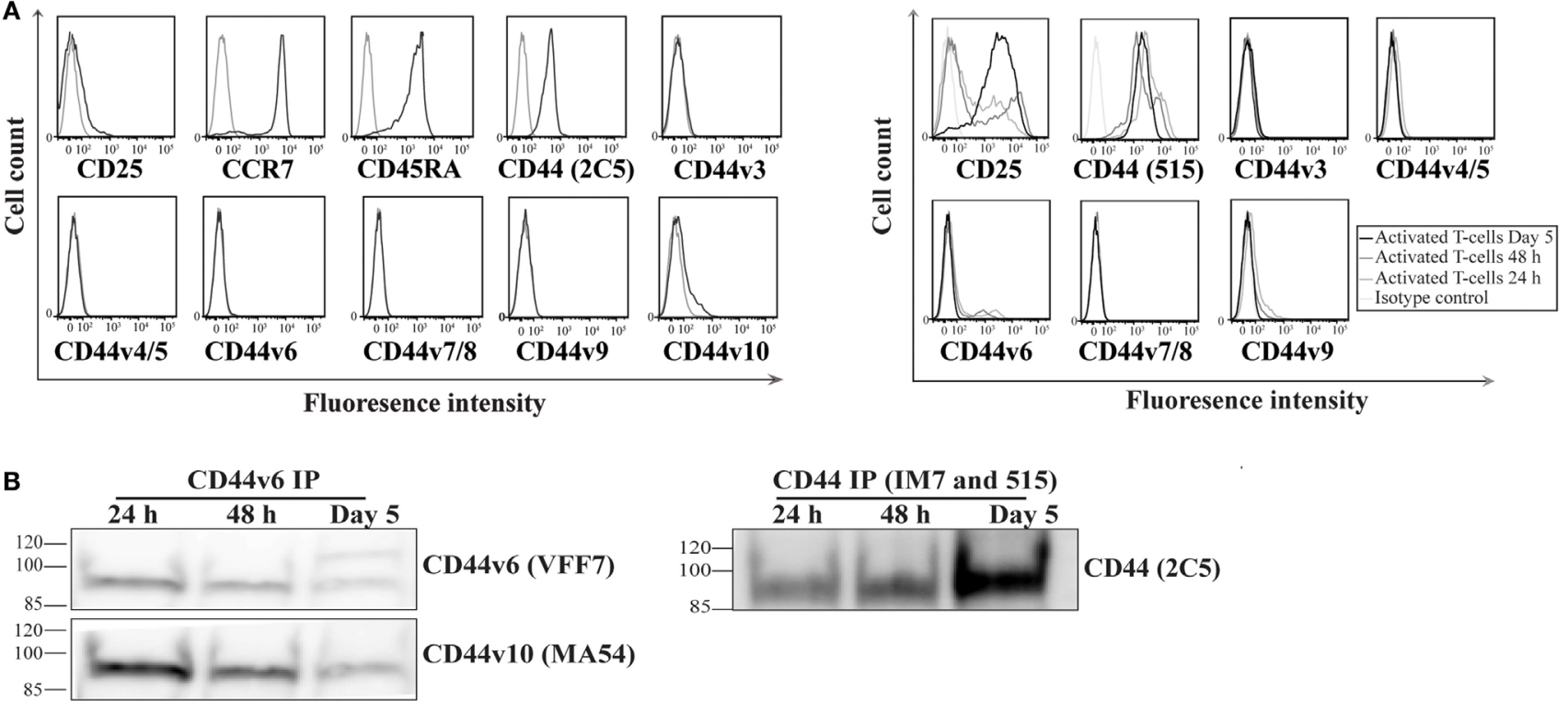

C

$24 \mathrm{~h}$

$48 \mathrm{~h}$

Day 5

IP: CD44s CD44v6
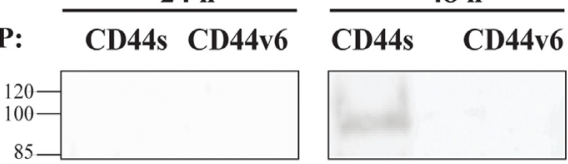

CD44s CD44v6

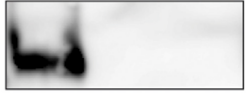

E-selectin staining

FIGURE 2 | CD44s, not CD44 variant (CD44v), is an E-selectin ligand on activated human T-cells. (A) To analyze the expression of CD44v on the surface of naive (left panel; CD25-CCR7 ${ }^{+}$CD $45 R^{+}$) and activated (right pane) T-cells at different time points after activation ( $24 \mathrm{~h}, 48 \mathrm{~h}$, and Day 5), the cells were incubated with monoclonal antibodies against specific CD44v isoforms (black line) or isotype controls (gray line) and analyzed by flow cytometry. The activity of the CD44v antibodies were confirmed using breast cancer cell lines (Figure S5 in Supplementary Material). (B) CD44v6 (left panel) and CD44s (right panel) were consecutively immuo-purified from cell lysates prepared at different time points (24 h, $48 \mathrm{~h}$, and Day 5), subjected to Western blot analysis and stained with CD44v6 and CD44v10 (left panel) and CD44s (right pane). The protein immuno-purified by the anti-CD44v6 also stained positive for CD44v10 (left pane), which indicates that activated T-cells express a form of CD44 that comprises both exon 6 and exon 10. (C) Western blot analysis of immuno-purified CD44s and CD44v6 illustrates that E-selectin interacts with CD44s but not CD44v6/10. This interaction was time dependent initially detected at $48 \mathrm{~h}$ and increasing significantly at Day 5 . Immuno-purification for CD44 ( $\mathrm{s}$ and v) was performed from cell lysates that were normalized for cell number at each time point ( $24 \mathrm{~h}, 48 \mathrm{~h}$, and Day 5 ). Data are representative of $n=3$ independent experiments.

or the association rate of CD44/E-Ig and PSGL-1/E-Ig $(P=0.3$ and 0.8 , respectively). Overall, these results demonstrated that both PSGL-1 and CD44/HCELL isolated from activated human T-cells bound E-Ig with similar kinetics which is consistent with the affinity and kinetics evaluated for CD44/HCELL and PSGL-1 from the human leukemic progenitor cell line KG1a with E-Ig (40). These results are further supported by the data we obtained from the blot rolling assay, in which both ligands were able to support the rolling of $\mathrm{CHO}-\mathrm{E}$ cells with similar binding velocity.

To expand upon the limited information available on the stoichiometry of E-selectin binding to its ligands, we proceeded to quantify the stoichiometry of recombinant E-selectin binding to CD44/HCELL and PSGL- 1 in 150-mM NaCl buffer. To achieve this, we calculated the observed maximum number of response units using Eqs 2 and 3 in Supplementary Material. While only $60 \pm 23 \%$ (mean \pm SEM; $n=4)$ of captured CD44/HCELL was appropriately oriented and/or glycosylated to bind E-Ig, around $221 \pm 72 \%$ (mean \pm SEM; $n=4$ ) of PSGL- 1 could bind indicating that a minimum of two E-selectin dimers interacts with a dimer of PSGL-1. Collectively, these results indicate that although the intrinsic binding kinetics of both ligands are similar, variation could occur due to differences in the avidity of their individual binding sites, the degree of posttranslational modifications on the ligands, and/or the expression level of each ligand. Indeed, the CD44 antibodies used for these experiments are not specific to any specific glycoform of CD44 so they are likely capturing a mixture of glycoforms of CD44 and the HCELL glycoform is able to bind E-Ig, while the others do not as previously discussed (40).

\section{Both CD44/HCELL and PSGL-1 Are Essential for E-Selectin Binding of Human Activated T-Cells}

To date, antibodies that block specific ligand binding to E-selectin have not been described, making it difficult to compare the contribution of individual ligands to the overall E-selectin binding of a cell. Furthermore, differences in the expression levels of different ligands and their immuno-purification efficiency pose 
A

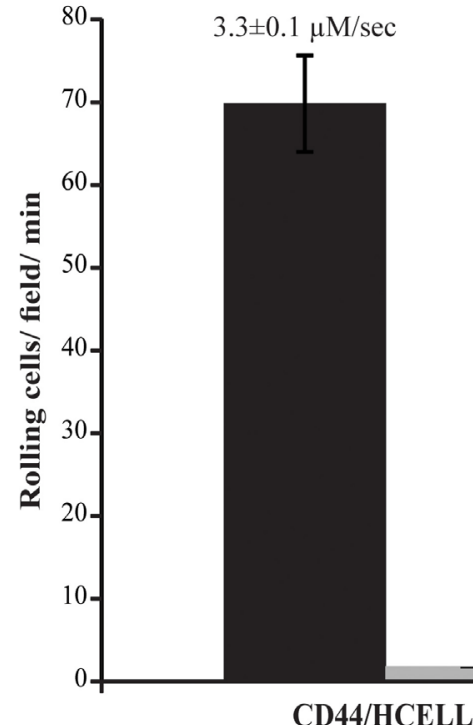

B
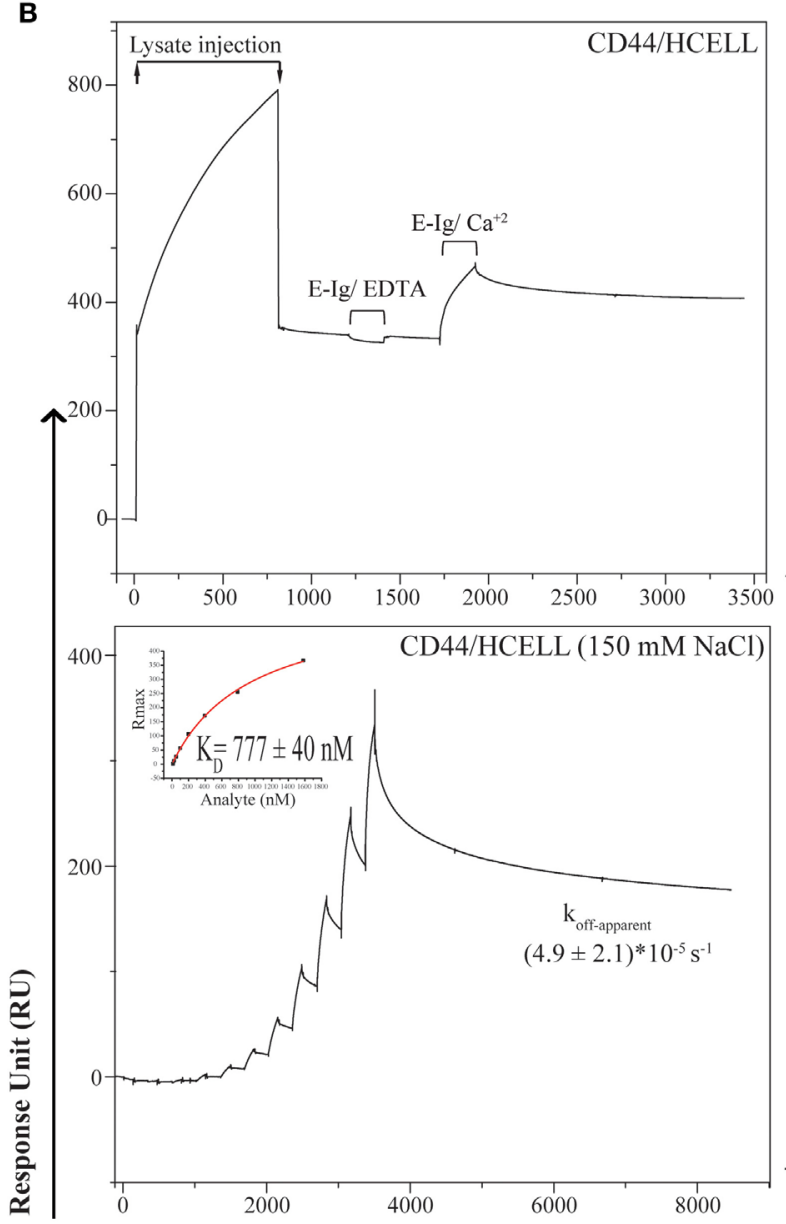

$\mathrm{CHO}-\mathrm{E}+\mathrm{Ca}^{2+}$

CHO-E+ EDTA
$2.6 \pm 0.1 \mu \mathrm{M} / \mathrm{sec}$

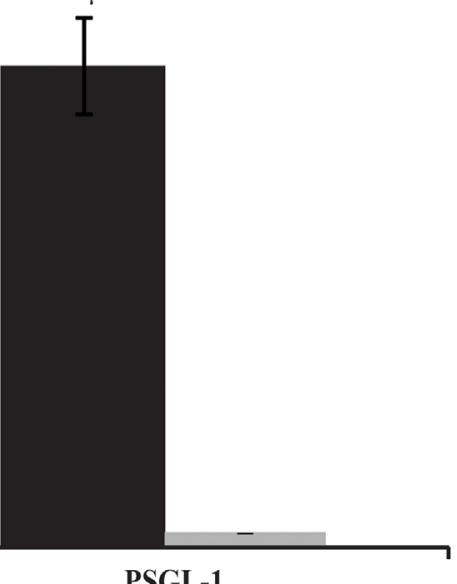

PSGL-1
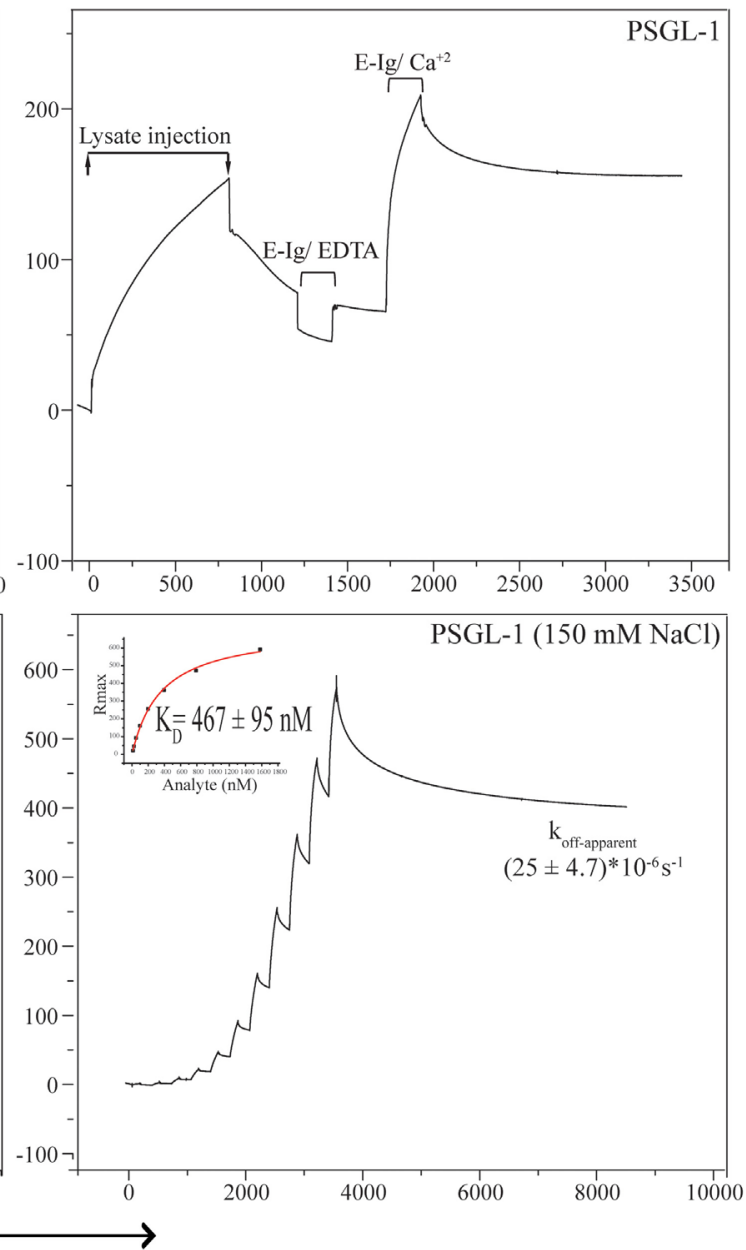

Time (s)

FIGURE 3 | Continued 
FIGURE 3 | Continued

CD44/HCELL is a functional E-selectin ligand on activated human T-cells. (A) Blot rolling assays were performed on immuno-purified CD44/HCELL and P-selectin glycoprotein ligand-1 (PSGL-1). Initially, immuno-purified protein was resolved by SDS-PAGE. Then, CHO-E cells were allowed to roll over immunopurified proteins in the presence of $2-\mathrm{mM} \mathrm{Ca}^{2+}$ at $0.5 \mathrm{dyn} \mathrm{cm}^{-2}$. After cell perfusion, the numbers of rolling cells per square millimeter in five distinct fields of view were counted and the average is presented (black bars). The specificity of CHO-E binding to membrane glycoproteins was assessed by adding 5 -mM EDTA to the buffer containing $\mathrm{CHO}$-E cells (gray bars). The $x$-axis reflects the mean of rolling cells per field per minute from one representative experiment of multiple independent membrane preparations $(n=3)$. The mean velocity \pm SEM of rolling cells was determined and presented here on top of the bars. (B) BIAcore assay was performed to determine the ability of native CD44/HCELL and PSGL-1 to bind E-lg. To determine the ability of captured protein to bind E-lg, we injected 100-nM of E-lg at $20 \mu \mathrm{l} \mathrm{min}{ }^{-1}$ over the native CD44/HCELL or PSGL-1 (upper pane/s) in the presence of 5-mM EDTA to control for specificity or 1 -mM Ca ${ }^{2+}$ to study the binding. To determine the kinetics of the CD44/HCELL interaction with E-Ig and compare it to that with PSGL-1 (Iower pane/s), monoclonal antibodies or their isotype controls were immobilized on the chip, and then the ligands were captured. Afterward, a series of 10 E-Ig concentrations $(0.456-466.7 \mathrm{nM})$ were injected at $30 \mu \mathrm{l}$ min ${ }^{-1}$ over CD44/HCELL or PSGL-1 in 150-mM NaCl running buffer. The equilibrium dissociation constant (KD) was derived from fitting the binding isotherm using the steady-state model and the maximum response unit (RUmax) of E-lg binding just before the washing step. After the last E-lg injection, we determined the apparent dissociation rate constant ( $\left.K_{\text {off-apparent }}\right)$ by fitting the stable phase obtained during the buffer wash. Data shown here are the mean \pm SEM of $n=3$, after the correction against the bulk refractive index and subtraction of the non-specific binding of the isotype control.

challenges to comparative analysis. Moreover, no gene-targeted silencing studies of E-selectin ligands have been conducted on primary activated human T-cells or on any other primary human cells to our knowledge. To this end, we used a siRNA-mediated knockdown approach to dampen the expression of CD44 (i.e., HCELL) and PSGL-1 either individually or in tandem and assessed effects on E-selectin-mediated cell rolling. Individual cell membrane proteins exhibit different turnover rates; therefore, we predicted that these proteins persist even after successful knockdown of their mRNAs and elicit a false impression of incomplete silencing. To circumvent this issue, we used bromelain to remove cell surface proteins prior to transfection. Western blot analysis verified that this procedure resulted in a more thorough knockdown of the cell surface proteins, which was more pronounced on the knockdown of CD44 than on the PSGL-1 knockdown (Figure 4A), likely due to a variation in the turnover rates between the two ligands. As shown in a representative Western blot in Figure 4B, effective knockdown was observed in the single knockdowns (CD44, PSGL-1, and CD43), the double knockdown (CD44 and PSGL-1), and the triple knockdown (CD44, PSGL-1, and CD43). Furthermore, the expression level of non-targeted ligands remained consistent among all treatments confirming the specificity of each siRNA.

To investigate the impact of ligand silencing on E-selectinmediated rolling, activated human T-cells transfected with CD44, PSGL-1, double, CD43, or triple siRNAs were perfused over a monolayer of CHO-E cells under several shear stress conditions (1-5 dyn $\left.\mathrm{cm}^{-2}\right)$. Cells transfected with a scrambled control siRNA maintained high numbers of rolling interactions on CHO-E cells at all shear stress rates; however, in the absence of CD44/HCELL and/or PSGL-1, a marked reduction in the number of rolling cells at shear stress $\geq 1$ dyn $\mathrm{cm}^{-2}$ was observed (Figure 4C; Videos S3-S8 in Supplementary Material). Knockdown of both ligands did not result in a synergistic decrease in rolling behavior, beyond that observed in the individual knockdowns, strongly suggesting that the presence of both CD44/HCELL and PSGL-1 was essential to confer rolling over CHO-E cells (Figure 4C; Videos S3-S8 in Supplementary Material). Unlike CD44/HCELL and PSGL-1, the knockdown of CD43 did not affect the number of rolling cells. Moreover, loss of CD43 from the triple knockdown did not result in further decreases in the number of rolling cells compared with the number with double knockdown, indicating that CD43 minimally contributed to E-selectin-mediated rolling. The function of CD43 in T-cell migration is conflicting: some data implicate it as an anti-adhesive (42-44) molecule while others as a pro-adhesive one $(19,20,45,46)$; however, in this study, we could not confirm the pro-adhesive role of CD43 on activated human T-cells mainly comprised of a Th2 phenotype (Table S2 in Supplementary Material). Furthermore, in the absence of both of these ligands, some binding to E-selectin still persists, likely due to glycolipids (47), existence of low levels of CD44 (Figure 4B), and/or other minor glycoprotein ligands as outlined in our mass spectrometry study (Table 1).

\section{CD44/HCELL on T-Cells Isolated from Psoriatic Patients Binds E-selectin}

The aforementioned results showed that CD44/HCELL from in vitro-activated T-cells possess E-selectin-binding activity. Next, we examined whether the ability of CD44/HCELL to bind E-selectin would be preserved under in vivo stimulation. To this end, we isolated circulating T-cells from patients suffering from the chronic skin inflammatory disease, psoriasis. Many studies have implicated that E-selectin plays a key role in the excessive infiltration of memory T-cells to the skin that manifests as psoriasis $(6,48-50)$. Moreover, several studies have confirmed the importance of circulating T-cells bearing the HECA-452 antigenic determinant in the clinical manifestation of psoriasis $(51,52)$. We confirmed the expression of HECA on circulating T-cells isolated from psoriatic patients using flow cytometric analysis (Figure 5A). The percentage of T-cells expressing HECA was significantly higher in psoriatic patients than in healthy donors $(P$-value $=0.007), 36 \pm 4.3 \%($ mean \pm SEM; $n=4)$ versus $10.6 \pm 3 \%$ (mean $\pm \mathrm{SEM} ; n=3$ ), respectively. We next immuno-purified E-selectin ligands from T-cells isolated from psoriatic patients and tested their interaction with E-selectin. As illustrated in Figure 5B, CD44/HCELL and PSGL-1 bound E-selectin. Similar to our in vitro-activated T-cell results, a very weak interaction was observed between CD43 and E-selectin. Overall, this study identifies CD44/HCELL as an E-selectin ligand on activated human T-cells and suggests that it may play an important role in the regulation of T-cell migration and/or trafficking in skin diseases. 


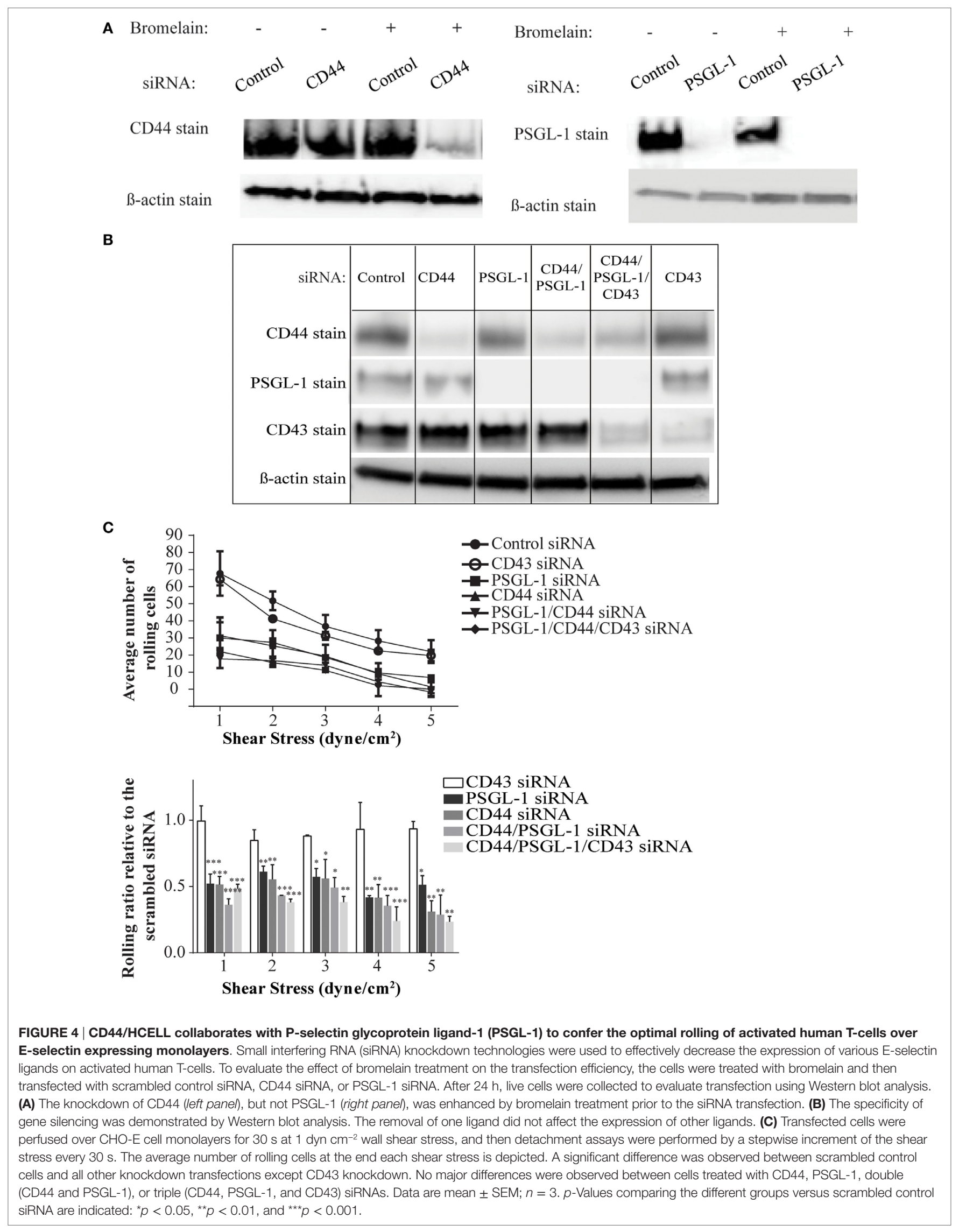




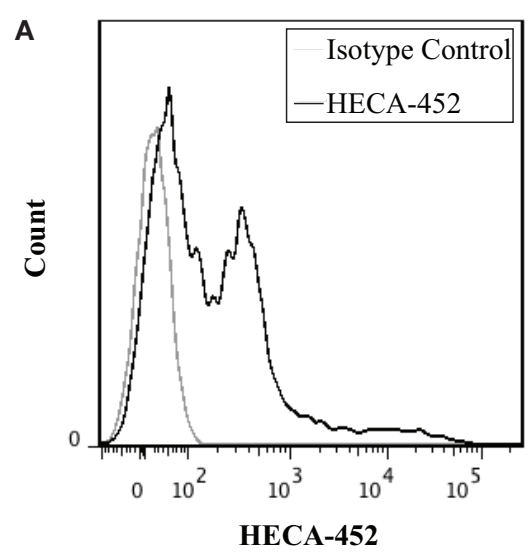

B

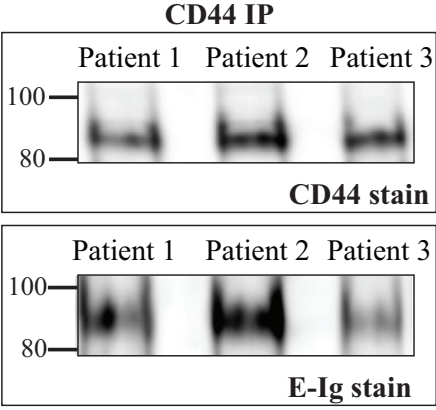

PSGL-1 IP
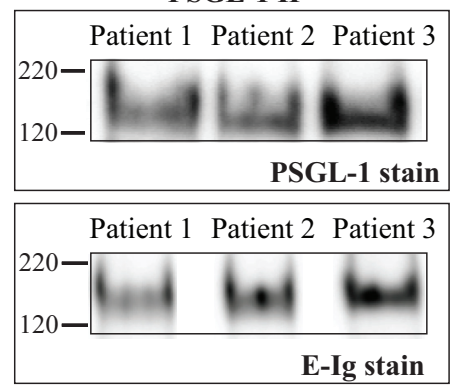

CD43 IP
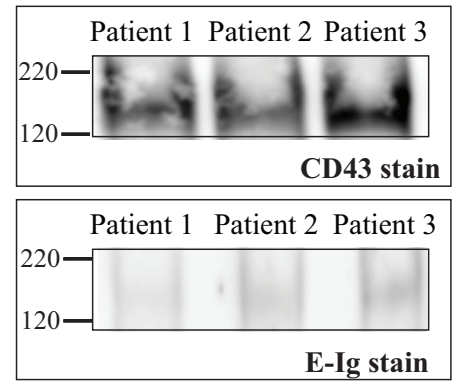

FIGURE 5 | CD44/HCELL on T-cells from psoriatic patients binds E-selectin. (A) Expression of sialofycosylated glycans on T-cells isolated from psoriatic patients. After isolation of $\mathrm{CD}^{+}$cells from psoriatic patients (representing mixed subsets as illustrated in Table S2 in Supplementary Material), we performed flow cytometry analysis to confirm the expression of sialofycosylated glycans using HECA-452 antibody. (B) CD44, P-selectin glycoprotein ligand-1 (PSGL-1), and CD43 were immuno-purified from T-cells obtained from three psoriatic patients and then samples were prepared for Western blot analysis and blotted for each ligand (upper pane/s) and for E-lg (lower pane/s). Note that CD44/HCELL and PSGL-1 exhibit strong binding to E-Ig, while CD43 binding was very weak.

\section{DISCUSSION}

CD44 has a well-established role in T-cell migration via its interactions with HA (30) and the integrin VLA-4 (53). Here, we provide compelling evidence that CD44/HCELL expressed by in vitro- and in vivo-activated human T-cells can mediate T-cell interactions with E-selectin. We showed that CD44/HCELL bound E-selectin in a transient and specific manner and that this interaction supported cell rolling under physiological shear stress conditions similar to the well-described E-selectin ligand PSGL1. In fact, our data demonstrate that CD44/HCELL mediates this action through cooperation with PSGL-1.

Several E-selectin ligands have been identified on mature myeloid cells, hematopoietic progenitor cells, cancerous cells, and lymphocytes $(18,27,42-44,54)$. To date, only two of these ligands, PSGL-1 and CD43, are reported to be E-selectin ligands on activated human T-cells $(19,20)$. Studies in mice showed that a concomitant deficiency of these ligands did not completely abolish E-selectin-mediated T-cell rolling (20), suggesting the requirement of another E-selectin ligand(s). Moreover, reports on the role of CD43 in T-cell migration show conflicting results: some works propose its anti-adhesive role $(42-44,54)$ and others propose its pro-adhesive role (19, 20, 45, 46, 55). Therefore, we performed a mass spectrometry-based analysis that showed additional E-selectin ligands are present on activated human T-cells, such as CD44 as well as some other ligands that require confirmation for their ability to bind E-selectin. Herein, we characterize the role of CD44 in E-selectin-mediated T-cell rolling, and in future work, we plan to determine the relevance of the remaining candidate ligands.

Previous works identified that CD44 is an E-selectin ligand on several different types of cells, such as HSPCs, neutrophils, mouse Th1 cells, breast cancer cells, colon carcinoma cells, and melanoma $(24,26,28,29,41,56)$. Actually, a specialized glycoform of CD44 is able to bind E-selectin and based on the extensive biochemical characterization of this binding, the E-selectin binding form of CD44 became known as HCELL. In a number of recent reviews, HCELL is described as a sialofucosylated glycoform of CD44, originally found on HSPCs, that acts as an E-selectin and/or L-selectin ligand $(57,58)$. CD44 isolated from activated human T-cells stains for antibodies that recognize sialofucosylated glycans (mainly HECA-452, CSLEX-1, and KM93, Figure S3 in Supplementary Material). However, the signal we detect with CD44 is weaker than the PSGL-1 signal. This weaker signal with HECA-452 mAb might explain why CD44 was missed in previous studies on activated human T-cells in which researchers were focusing on identifying ligands that displayed strong HECA-452staining signal (19). Similar to earlier reports, the importance of 
$\mathrm{N}$-glycans in mediating the interaction of E-selectin binding to CD44/HCELL $(26,27,40)$ on primary HSPCs was also demonstrated here on activated human T-cells. Interestingly, previous work has shown that $\mathrm{N}$-glycosylation is predominant on CD44s, whereas $\mathrm{O}$-glycosylation is more predominant on CD44v (24). This is consistent with our finding that E-selectin binding form of CD44/HCELL on activated human T-cells is indeed CD44s.

In an effort to characterize the binding affinity and kinetics between the dimer form of E-selectin (E-Ig) and CD44/HCELL or PSGL-1 from activated human T-cells, we used the real-time BIAcore technique. Our results were consistent with a previous study that evaluated the affinity and kinetics between E-Ig and CD44/HCELL or PSGL-1 from the human leukemic progenitor cell line KG1a (40). Although both ligands bound to E-Ig with a similar affinity at a physiological salt concentration of $150-\mathrm{mM} \mathrm{NaCl}$, the ligands bind to E-Ig with different valences: one dimer of PSGL-1 interacted with a minimum of two dimers of E-selectin and almost half of the CD44 bound E-selectin. The remaining CD44 may be inadequately stained with HECA or inappropriately oriented on the surface of the CM5-Chip to interact with E-selectin. Since the CD44 antibodies are not specific for the HCELL glycoform, at least partially inadequate glycosylation of the remaining CD44 is likely a reason for the observed stoichiometry as previously noted (40). The finding that both CD44/HCELL and PSGL-1 bound to E-selectin with similar kinetics was further supported by the data we obtained from the blot rolling assay, in which both ligands were able to support the rolling of $\mathrm{CHO}-\mathrm{E}$ cells with similar binding velocity.

Using a knockdown approach on primary human T-cells, we dampened the expression of CD44/HCELL, PSGL-1, and CD43 either individually or together to determine the importance of each ligand on E-selectin binding. We found that the success of CD44 (and HCELL) transfection was dependent on treating activated cells with bromelain prior to the transfection to remove any previously expressed proteins. While bromelain treatment was not required for effective knockdown of PSGL-1, we attributed the more thorough knockdown with the treatment to a variation in the turnover rates between the two ligands. The parallel plate flow assay on transfected cells showed that the loss of either CD44/HCELL or PSGL-1 had an adverse impact on the rolling capacity of the activated T-cells over CHO-E cells. The simultaneous knockdown of both ligands did not result in a synergistic decrease in rolling behavior, which strongly suggests that both CD44/HCELL and PSGL-1 collaborate to confer efficient rolling of activated human T-cells over CHO-E cells. Furthermore, in the absence of both CD44/HCELL and PSGL-1, we continued to observe residual binding to E-selectin, which we attributed to the availability of glycolipids $(47,59)$ as well as other minor glycoprotein ligands. Potentially, some of these minor ligands might have been detected by the mass spectroscopy studies we conducted (Table 1; Table S1 in Supplementary Material). Further studies are required to assess the interactions of E-selectin with these candidate ligands under physiological shear stress conditions.

We could not confirm the pro-adhesive role of CD43 on activated human T-cells. The removal of CD43 in CD43 siRNA transfected cells did not affect the rolling capacity when compared with scrambled siRNA transfected cells. In addition, the removal of CD43 in the triple knockdown did not significantly decrease E-selectin-mediated rolling beyond the decrease we noticed in the CD44/HCELL and PSGL-1 double knockdown. Furthermore, the minimal contribution of CD43 to E-selectin binding in chronic skin disease was evident when immuno-purified CD43 from psoriatic patients retained an extremely weak interaction with HECA-452 and E-selectin. Detection of binding between E-selectin and CD43 in both the mass spectrometric and Western blot analyses could be explained by the nature of these assays: both are static, unlike parallel plate flow chamber assays, blot rolling assay, and BIAcore (data not shown), which rely on flow. Thus, it is possible that the application of mechanical load on CD43 in the later assays caused shear-induced conformational changes (60) that buried E-selectin-binding sites on CD43 and disrupted its binding activity. In addition, it is unclear whether the expression of HECA-452-reactive epitope on any protein by itself is sufficient to qualify it as a functional E-selectin ligand. Moreover, although CD43 may not specifically contribute to E-selectin-binding interactions, its importance in binding to other potential ligands such as ICAM-1 and galectin-1 $(61,62)$ should not be overlooked given that these ligands are expressed by inflamed endothelium and that the administration of human recombinant galectin-1 can inhibit leukocyte rolling and extravasation (63).

E-selectin-specific inhibitors are currently being investigated for their positive effects on acute myeloid leukemia and sickle cell disease (64-66). By inhibiting selectin interactions, GMI-1070 can decrease leukocyte adhesion and recruitment to inflamed tissues in various disorders, such as the inflamed venules in sickle cell disease, an essential event initiating vaso-occlusion in this disease. In animal models, GMI-1070 also appears to inhibit the homing of multiple myeloma cells to the bone marrow and improves the efficacy of the proteasome inhibitor, bortezomib, which is currently used to treat the disease (67). This is an attractive therapeutic target in autoimmune inflammatory diseases such as rheumatoid arthritis and psoriasis in which the expression of E-selectin has been shown to be responsible for the pathological accumulation of active immune cells such as lymphocytes $(8,68)$. For example, in psoriasis patients, the administration of a pan-selectin inhibitor (Bimosiamose) resulted in a reduction of lymphocyte infiltration and an overall clinical improvement (69). However, the long-term use of pan inhibitors might interfere with vital interactions relating to homeostasis such as the migration of HSCs to the bone marrow $(27,70)$ and in immune cell migration to infected tissues $(9,71)$. Therefore, targeting specific E-selectin ligand(s) may be a more attractive treatment strategy.

To the best of our knowledge, limited studies have looked into identifying all the E-selectin ligands involved in the recruitment of T-cells in psoriasis and/or any other inflammatory skin disorders. Here, we show evidence that both CD44 (and specifically HCELL) and PSGL-1 immuno-purified from psoriatic patients interacts with E-selectin. Based on these data, we can envision targeting these ligands. Indeed, CD44 blocking antibodies caused a marked reduction in leukocyte infiltration in experimental models of inflammatory diseases $(72,73)$. In those studies, the 
apparent infiltration was mainly attributed to the blocking of HA-mediated leukocytes migration. However, neither the inhibition of T-cells nor the contribution of E-selectin-mediated rolling was assessed as the role of CD44/HCELL as an E-selectin ligand on activated human T-cells was not yet discovered. We believe that targeting the E-selectin-binding site on CD44/HCELL could be a viable option to treat skin diseases, such as psoriasis, for a number of reasons relating to homeostasis. Being unable to interact with P-selectin, blocking antibodies against CD44/ HCELL can interfere with E-selectin-mediated cell rolling while sustaining the proper immune defense where its interaction with P-selectin is crucial. Moreover, blocking CD44/HCELL interactions with E-selectin may have minimal effects on stem cell homing (74) since many ligands (unpublished data from our lab) could compensate for inhibition of CD44/HCELL binding to E-selectin.

\section{EXPERIMENTAL PROCEDURES}

\section{Cells}

Frozen normal peripheral blood mononuclear cells isolated from subjects with and without psoriasis were ordered from AllCells (CA, USA). Naïve Pan T-cell Isolation Kit and Pan T-cell Isolation Kit (Miltenyi Biotec) were used to isolate T-cells. For activation, $10^{6}$ cells $\mathrm{ml}^{-1}$ of $\mathrm{CD}^{+}$cells were incubated with $5 \mu \mathrm{g} \mathrm{ml}{ }^{-1}$ of immobilized anti-CD3 (clone: OKT3, eBioscience) in RPMI media, 10\% FBS, $1 \mu \mathrm{g} \mathrm{ml} \mathrm{m}^{-1}$ anti-CD28 (BD Bioscience), and $100 \mathrm{U} \mathrm{ml}^{-1}$ of IL-2 for $36 \mathrm{~h}$. Then, cells were collected and cultured for 2 days with $100 \mathrm{U} \mathrm{ml}^{-1}$ of IL-2 only.

\section{Flow Cytometry Analysis}

CD25 was used as a T-cell activation marker. The presence of E-selectin ligands on T-cells was determined by assaying the binding of recombinant mouse E-selectin/CD62E Fc chimera (E-Ig) (R\&D). First, cells were washed and resuspended in HBSS containing $5 \% \mathrm{FBS}, 25-\mathrm{mM}$ HEPES, and $2-\mathrm{mM} \mathrm{CaCl}_{2}$ or $10-\mathrm{mM}$ EDTA (negative control) and then stained for $30 \mathrm{~min}$ at $4^{\circ} \mathrm{C}$ with E-Ig followed by biotin-conjugated mouse anti-human IgG antibody; stained cells were recognized by PE-labeled streptavidin. Binding was detected using the FACSCanto II and analyzed using FlowJo software.

\section{Deglycosylation Assay}

Immuno-purified proteins were treated with $20 \mathrm{mU} \mathrm{ml}^{-1}$ PNGase (NEB), $0.1 \mathrm{U} \mathrm{ml}^{-1}$ sialidase (Roche), or $120 \mu \mathrm{g} \mathrm{ml}^{-1}$ of OSGE (Cedarlane); treatments with PNGase or OSGE were performed for $4 \mathrm{~h}$ at $37^{\circ} \mathrm{C}$, and the sialidase treatment was done in HBSS with $5-\mathrm{mM} \mathrm{CaCl}_{2}$ for $3 \mathrm{~h}$ at $37^{\circ} \mathrm{C}$. As a control, each treatment was performed under the same conditions with no added enzymes.

\section{Blot Rolling Assay}

This assay was carried out as previously reported $(75,76)$. Briefly, $\mathrm{CHO}$ cells expressing E-selectin (CHO-E) were harvested with
10-mM EDTA, washed, and resuspended in HBSS (135-mM $\mathrm{NaCl}$ ) at $10^{7}$ cells $\mathrm{ml}^{-1}$. Western blot membranes of immunopurified PSGL-1 or CD44/HCELL were stained with HECA or $2 \mathrm{C} 5$ antibody, respectively, and rendered transparent using HBSS, 2-mM Ca ${ }^{2+}$, and $10 \%$ glycerol. Next, the blots were placed in the parallel plate flow chamber, $10^{6}$ cells were perfused into the chamber at a shear stress rate of $0.5 \mathrm{dyn} \mathrm{cm}^{-2}$, and rolling cells were captured on videotape. The number of rolling cells and the cell displacement on the $Y$-axis over time (velocity, micrometers per second) for both proteins were determined using Imaris V7 software (Bitplane). Only cells with a minimum diameter of $10 \mu \mathrm{m}$ and with minimum threshold intensities were included in the analyses. To count the number of rolling cells, those that moved less than four frames or had a total displacement of less than $10 \pm 3 \mu \mathrm{m}$ were considered non-specific and eliminated from the analysis. To measure the velocity, we plotted the position of each rolling cell at any one field (micrometers) over time (seconds) and then calculated the fitted slope as an indicator of the average velocity.

\section{BIAcore Analysis}

The assay was carried out as described previously (40); mAbs against CD44 and PSGL-1 were directly immobilized over CM5 sensor chip by amine coupling to capture the native proteins from the fresh T-cell lysate. Details are supplied in experimental procedures in Supplementary Material.

\section{Gene-Targeted Knockdown of CD44, PSGL-1, and CD43}

T-cells were activated as described above, and on Day 2 of activation, the cells were collected and treated for $7 \mathrm{~min}$ at $37^{\circ} \mathrm{C}$ with $1 \mathrm{mg} \mathrm{ml}^{-1}$ of bromelain (Sigma) in RPMI media with $10 \%$ FBS to preferentially cleave the carbonyl ends of lysine, alanine, tyrosine, and glycine. The cells were then washed three times in media and prepared for transfection. To knock down CD44, we used 50 pmol of the siRNA sequences s2681 and s2682; to knock down PSGL-1, we used 100 pmol of s12688; and to knock down CD43, we used 140 pmol of s13368 (Silencer Select, Life Technologies). Negative control no. 1 was used as the scrambled sequence for the transfection (Silencer Select, Life Technologies; 4390843). The cells were transfected according to the company protocol (Lonza) using the P3 Primary Cell 4D X Kit (V4XP). After $24 \mathrm{~h}$ of transfection, dead cells were removed by Ficoll separation and live cells were collected for parallel plate flow chamber assay and Western blot analysis.

\section{Parallel Plate Flow Chamber Assay}

Transfected cells were resuspended in $\mathrm{HBSS} / 2-\mathrm{mM} \mathrm{CaCl}_{2}$ $\left(10^{6}\right.$ cells $\left.\mathrm{ml}^{-1}\right)$ and perfused over a confluent monolayer of $\mathrm{CHO}-\mathrm{E}$ cells at shear stresses starting from $0.3 \mathrm{dyn}^{-2}$ for $2 \mathrm{~min}$ followed by gradual increases every $30 \mathrm{~s}$ from 1 to $5 \mathrm{dyn} \mathrm{cm}^{-2}$. Experiments were observed in real time and videotaped for analysis. Statistical analysis was performed using one-way ANOVA followed by multiple comparisons and a Tukey's test for correction (GraphPad Prism). 


\section{Online Supplementary Material}

Detailed methods and representative videos of the cell rolling experiments shown in Figure $\mathbf{1}$ and the blot rolling assays in Figure $\mathbf{3}$ are available in experimental procedures in Supplementary Material.

\section{AUTHOR CONTRIBUTIONS}

AJA designed, performed, and analyzed experiments and wrote the manuscript. AFA helped in designing and conducting the cell-rolling experiments, maintaining cancer cell lines, and discussing the results. JM designed and analyzed experiments and wrote the manuscript.

\section{ACKNOWLEDGMENTS}

The authors would like to thank Dr. Samir M. Hamdan for discussions regarding SPR studies and Ms. Samar A. Rostom for her support in the management of the lab. The authors would also like to thank Carolyn Unck from the Academic Writing Services at KAUST for editing the manuscript. In addition, a special thanks to Dr. Aswini K. Panigrahi from the Bioscience Core Lab facility for the mass spectrometry assistance and the rest of the members of the Cell Migration and Signaling Laboratory for their support.

\section{REFERENCES}

1. Parisi R, Symmons DPM, Griffiths CEM, Ashcroft DM. Global epidemiology of psoriasis: a systematic review of incidence and prevalence. J Invest Dermatol (2013) 133:377-85. doi:10.1038/jid.2012.339

2. Raychaudhuri SK, Maverakis E, Raychaudhuri SP. Diagnosis and classification of psoriasis. Autoimmun Rev (2014) 13:490-5. doi:10.1016/j.autrev.2014.01.008

3. Di Cesare A, Di Meglio P, Nestle FO. The IL-23/Th17 axis in the immunopathogenesis of psoriasis. J Invest Dermatol (2009) 129:1339-50. doi:10.1038/ jid.2009.59

4. Teunissen MB, Munneke JM, Bernink JH, Spuls PI, Res PC, Te Velde A, et al. Composition of innate lymphoid cell subsets in the human skin: enrichment of NCR(+) ILC3 in lesional skin and blood of psoriasis patients. J Invest Dermatol (2014) 134:2351-60. doi:10.1038/jid.2014.146

5. Von Andrian UH, Mempel TR. Homing and cellular traffic in lymph nodes. Nat Rev Immunol (2003) 3:867-78. doi:10.1038/nri1222

6. Masopust D, Schenkel JM. The integration of T cell migration, differentiation and function. Nat Rev Immunol (2013) 13:309-20. doi:10.1038/nri3442

7. Butcher EC. Leukocyte-endothelial cell recognition: three (or more) steps to specificity and diversity. Cell (1991) 67:1033-6. doi:10.1016/0092-8674(91) 90279-8

8. Luster AD, Alon R, Von Andrian UH. Immune cell migration in inflammation: present and future therapeutic targets. Nat Immunol (2005) 6:1182-90. doi:10.1038/ni1275

9. Ley K, Kansas GS. Selectins in T-cell recruitment to non-lymphoid tissues and sites of inflammation. Nat Rev Immunol (2004) 4:325-35. doi:10.1038/nri1351

10. Sperandio M. Selectins and glycosyltransferases in leukocyte rolling in vivo. FEBS J (2006) 273:4377-89. doi:10.1111/j.1742-4658.2006.05437.x

11. Dohlman TH, Di Zazzo A, Omoto M, Hua J, Ding J, Hamrah P, et al. E-selectin mediates immune cell trafficking in corneal transplantation. Transplantation (2016) 100:772-80. doi:10.1097/TP.0000000000001107

12. Yamada S, Mayadas TN, Yuan F, Wagner DD, Hynes RO, Melder RJ, et al. Rolling in P-selectin-deficient mice is reduced but not eliminated in the dorsal skin. Blood (1995) 86:3487-92.

13. Tietz W, Allemand Y, Borges E, Von Laer D, Hallmann R, Vestweber D, et al. $\mathrm{CD} 4+\mathrm{T}$ cells migrate into inflamed skin only if they express ligands for $\mathrm{E}$ - and P-selectin. J Immunol (1998) 161:963-70.

\section{FUNDING}

This work was supported by the King Abdullah University of Science and Technology (KAUST) Faculty Baseline Research Funding Program as well as a Competitive Research Grant (CRG2_R2_13_MERZ_KAUST_1) to JM.

\section{SUPPLEMENTARY MATERIAL}

The Supplementary Material for this article can be found online at http://journal.frontiersin.org/article/10.3389/fimmu. 2017.00492/full\#supplementary-material.

VIDEOS S1 and S2 | The videos show the data from blot rolling assays that were performed on immuno-purified CD44 (Video 1) and PSGL-1 (Video 2) from activated human T-cells. Refer to Figure 3A. Videos were recorded and analyzed at 1 frame $\mathrm{s}^{-1}$ but for presentation purposes are displayed at 5 frames $\mathrm{s}^{-1}$.

VIDEOS S3-S8 | Examples of rolling activated human T-cells transfected with various knockdown siRNAs to assess the effect of ligands on migration over E-selectin expressing $\mathrm{CHO}$ cell monolayers. Video 3 , scrambled vector control; Video 4, CD44 siRNA; Video 5, CD162 (PSGL-1) siRNA; Video 6, double siRNA; Video 7, triple siRNA; and Video 8, CD43 siRNA. Refer to Figure 4C. Videos were recorded and analyzed at 1 frame $\mathrm{s}^{-1}$ but for presentation purposes are displayed at 5 frames $\mathrm{s}^{-1}$.

14. Schweitzer KM, Drager AM, Van Der Valk P, Thijsen SF, Zevenbergen A, Theijsmeijer AP, et al. Constitutive expression of E-selectin and vascular cell adhesion molecule- 1 on endothelial cells of hematopoietic tissues. Am J Pathol (1996) 148:165-75.

15. Liu Z, Miner JJ, Yago T, Yao L, Lupu F, Xia L, et al. Differential regulation of human and murine P-selectin expression and function in vivo. J Exp Med (2010) 207:2975-87. doi:10.1084/jem.20101545

16. Pan J, Xia L, Mcever RP. Comparison of promoters for the murine and human P-selectin genes suggests species-specific and conserved mechanisms for transcriptional regulation in endothelial cells. J Biol Chem (1998) 273:10058-67. doi:10.1074/jbc.273.16.10058

17. Gharib WH, Robinson-Rechavi M. When orthologs diverge between human and mouse. Brief Bioinform (2011) 12:436-41. doi:10.1093/bib/bbr031

18. Fuhlbrigge RC, Kieffer JD, Armerding D, Kupper TS. Cutaneous lymphocyte antigen is a specialized form of PSGL-1 expressed on skin-homing T cells. Nature (1997) 389:978-81. doi:10.1038/40166

19. Fuhlbrigge RC, King SL, Sackstein R, Kupper TS. CD43 is a ligand for E-selectin on CLA+ human T cells. Blood (2006) 107:1421-6. doi:10.1182/ blood-2005-05-2112

20. Matsumoto M, Shigeta A, Furukawa $Y$, Tanaka T, Miyasaka M, Hirata T. CD43 collaborates with P-selectin glycoprotein ligand-1 to mediate E-selectindependent $\mathrm{T}$ cell migration into inflamed skin. JImmunol (2007) 178: 2499-506. doi:10.4049/jimmunol.178.4.2499

21. Carlow DA, Ziltener HJ. CD43 deficiency has no impact in competitive in vivo assays of neutrophil or activated $\mathrm{T}$ cell recruitment efficiency. J Immuno (2006) 177:6450-9. doi:10.4049/jimmunol.177.9.6450

22. Bajorath J. Molecular organization, structural features, and ligand binding characteristics of CD44, a highly variable cell surface glycoprotein with multiple functions. Proteins (2000) 39:103-11. doi:10.1002/(SICI)1097-0134 (20000501)39:2<103::AID-PROT1 >3.3.CO;2-7

23. Screaton GR, Bell MV, Jackson DG, Cornelis FB, Gerth U, Bell JI. Genomic structure of DNA encoding the lymphocyte homing receptor CD44 reveals at least 12 alternatively spliced exons. Proc Natl Acad Sci U S A (1992) 89:12160-4. doi:10.1073/pnas.89.24.12160

24. Hanley WD, Burdick MM, Konstantopoulos K, Sackstein R. CD44 on LS174T colon carcinoma cells possesses E-selectin ligand activity. Cancer Res (2005) 65:5812-7. doi:10.1158/0008-5472.CAN-04-4557 
25. Stamenkovic I, Aruffo A, Amiot M, Seed B. The hematopoietic and epithelial forms of $\mathrm{CD} 44$ are distinct polypeptides with different adhesion potentials for hyaluronate-bearing cells. EMBO J (1991) 10:343-8.

26. Dimitroff CJ, Lee JY, Rafii S, Fuhlbrigge RC, Sackstein R. CD44 is a major E-selectin ligand on human hematopoietic progenitor cells. J Cell Biol (2001) 153:1277-86. doi:10.1083/jcb.153.6.1277

27. Merzaban JS, Burdick MM, Gadhoum SZ, Dagia NM, Chu JT, Fuhlbrigge RC, et al. Analysis of glycoprotein E-selectin ligands on human and mouse marrow cells enriched for hematopoietic stem/progenitor cells. Blood (2011) 118:1774-83. doi:10.1182/blood-2010-11-320705

28. Katayama Y, Hidalgo A, Chang J, Peired A, Frenette PS. CD44 is a physiological E-selectin ligand on neutrophils. J Exp Med (2005) 201:1183-9. doi:10.1084/ jem.20042014

29. Nacher M, Blazquez AB, Shao B, Matesanz A, Prophete C, Berin MC, et al. Physiological contribution of CD44 as a ligand for E-selectin during inflammatory T-cell recruitment. Am J Pathol (2011) 178:2437-46. doi:10.1016/j. ajpath.2011.01.039

30. Degrendele HC, Estess P, Picker LJ, Siegelman MH. CD44 and its ligand hyaluronate mediate rolling under physiologic flow: a novel lymphocyteendothelial cell primary adhesion pathway. J Exp Med (1996) 183:1119-30. doi:10.1084/jem.183.3.1119

31. Bonder CS, Clark SR, Norman MU, Johnson P, Kubes P. Use of CD44 by CD4+ Th1 and Th2 lymphocytes to roll and adhere. Blood (2006) 107:4798-806. doi:10.1182/blood-2005-09-3581

32. Mestas J, Hughes CC. Of mice and not men: differences between mouse and human immunology. J Immunol (2004) 172:2731-8. doi:10.4049/jimmunol. 172.5.2731

33. Sellers RS. Translating mouse models. Toxicol Pathol (2017) 45:134-45. doi:10.1177/0192623316675767

34. Sackstein R. Fulfilling Koch's postulates in glycoscience: HCELL, GPS and translational glycobiology. Glycobiology (2016) 26:560-70. doi:10.1093/ glycob/cww026

35. Xie H, Lim YC, Luscinskas FW, Lichtman AH. Acquisition of selectin binding and peripheral homing properties by $\mathrm{CD} 4(+)$ and $\mathrm{CD} 8(+) \mathrm{T}$ cells. J Exp Med (1999) 189:1765-76. doi:10.1084/jem.189.11.1765

36. Merzaban JS, Zuccolo J, Corbel SY, Williams MJ, Ziltener HJ. An alternate core 2 beta1,6-N-acetylglucosaminyltransferase selectively contributes to P-selectin ligand formation in activated CD8 T cells. JImmunol (2005) 174:4051-9. doi:10.4049/jimmunol.174.7.4051

37. Polley MJ, Phillips ML, Wayner E, Nudelman E, Singhal AK, Hakomori S, et al. CD62 and endothelial cell-leukocyte adhesion molecule 1 (ELAM-1) recognize the same carbohydrate ligand, sialyl-Lewis x. Proc Natl Acad Sci US A (1991) 88:6224-8. doi:10.1073/pnas.88.14.6224

38. Ponta H, Sherman L, Herrlich PA. CD44: from adhesion molecules to signalling regulators. Nat Rev Mol Cell Biol (2003) 4:33-45. doi:10.1038/ nrm1004

39. Gadhoum SZ, Madhoun NY, Abuelela AF, Merzaban JS. Anti-CD44 antibodies inhibit both mTORC1 and mTORC2: a new rationale supporting CD44induced AML differentiation therapy. Leukemia (2016) 30(12):2397-401. doi:10.1038/leu.2016.221

40. Abusamra DB, Al-Kilani A, Hamdan SM, Sakashita K, Gadhoum SZ, Merzaban JS. Quantitative characterization of e-selectin interaction with native CD44 and P-selectin glycoprotein ligand-1 (PSGL-1) using a real time immunoprecipitation-based binding assay. J Biol Chem (2015) 290:21213-30. doi:10.1074/jbc.M114.629451

41. Shirure VS, Liu T, Delgadillo LF, Cuckler CM, Tees DF, Benencia F, et al. CD44 variant isoforms expressed by breast cancer cells are functional E-selectin ligands under flow conditions. Am J Physiol Cell Physiol (2015) 308:C68-78. doi:10.1152/ajpcell.00094.2014

42. Ardman B, Sikorski MA, Staunton DE. CD43 interferes with T-lymphocyte adhesion. Proc Natl Acad Sci U S A (1992) 89:5001-5. doi:10.1073/pnas. 89.11 .5001

43. Manjunath N, Correa M, Ardman M, Ardman B. Negative regulation of T-cell adhesion and activation by CD43. Nature (1995) 377:535-8. doi:10.1038/377535a0

44. Stockton BM, Cheng G, Manjunath N, Ardman B, Von Andrian UH. Negative regulation of $\mathrm{T}$ cell homing by CD43. Immunity (1998) 8:373-81. doi:10.1016/ S1074-7613(00)80542-7
45. Alcaide P, King SL, Dimitroff CJ, Lim YC, Fuhlbrigge RC, Luscinskas FW. The 130-kDa glycoform of CD43 functions as an E-selectin ligand for activated Th1 cells in vitro and in delayed-type hypersensitivity reactions in vivo. J Invest Dermatol (2007) 127:1964-72. doi:10.1038/s.j.jid.5700805

46. Velazquez F, Grodecki-Pena A, Knapp A, Salvador AM, Nevers T, Croce KJ, et al. CD43 functions as an E-selectin ligand for Th17 cells in vitro and is required for rolling on the vascular endothelium and Th17 cell recruitment during inflammation in vivo. J Immunol (2016) 196:1305-16. doi:10.4049/ jimmunol.1501171

47. Alon R, Feizi T, Yuen CT, Fuhlbrigge RC, Springer TA. Glycolipid ligands for selectins support leukocyte tethering and rolling under physiologic flow conditions. J Immunol (1995) 154:5356-66.

48. Cai JP, Harris K, Falanga V, Taylor JR, Chin YH. UVB therapy decreases the adhesive interaction between peripheral blood mononuclear cells and dermal microvascular endothelium, and regulates the differential expression of CD54, VCAM-1, and E-selectin in psoriatic plaques. Br J Dermatol (1996) 134:7-16. doi:10.1046/j.1365-2133.1996.d01-750.x

49. Prinz JC. The role of T cells in psoriasis. J Eur Acad Dermatol Venereol (2003) 17:257-70. doi:10.1046/j.1468-3083.2003.00720.x

50. Ferran M, Romeu ER, Rincon C, Sagrista M, Gimenez Arnau AM, Celada A, et al. Circulating CLA+ T lymphocytes as peripheral cell biomarkers in T-cell-mediated skin diseases. Exp Dermatol (2013) 22:439-42. doi:10.1111/ exd.12154

51. Vugmeyster Y, Kikuchi T, Lowes MA, Chamian F, Kagen M, Gilleaudeau P, et al. Efalizumab (anti-CD11a)-induced increase in peripheral blood leukocytes in psoriasis patients is preferentially mediated by altered trafficking of memory CD8+ T cells into lesional skin. Clin Immunol (2004) 113:38-46. doi:10.1016/j.clim.2004.06.001

52. Harper EG, Simpson EL, Takiguchi RH, Boyd MD, Kurtz SE, Bakke AC, et al. Efalizumab therapy for atopic dermatitis causes marked increases in circulating effector memory CD4+ T cells that express cutaneous lymphocyte antigen. J Invest Dermatol (2008) 128:1173-81. doi:10.1038/sj.jid.5701169

53. Nandi A, Estess P, Siegelman M. Bimolecular complex between rolling and firm adhesion receptors required for cell arrest; CD44 association with VLA-4 in T cell extravasation. Immunity (2004) 20:455-65. doi:10.1016/ S1074-7613(04)00077-9

54. Woodman RC, Johnston B, Hickey MJ, Teoh D, Reinhardt P, Poon BY, et al. The functional paradox of CD43 in leukocyte recruitment: a study using CD43deficient mice. J Exp Med (1998) 188:2181-6. doi:10.1084/jem.188.11.2181

55. Onami TM, Harrington LE, Williams MA, Galvan M, Larsen CP, Pearson TC, et al. Dynamic regulation of $\mathrm{T}$ cell immunity by CD43. J Immunol (2002) 168:6022-31. doi:10.4049/jimmunol.168.12.6022

56. Zhang P, Goodrich C, Fu C, Dong C. Melanoma upregulates ICAM-1 expression on endothelial cells through engagement of tumor CD44 with endothelial E-selectin and activation of a PKCalpha-p38-SP-1 pathway. FASEB J (2014) 28:4591-609. doi:10.1096/f.11-202747

57. Jacobs PP, Sackstein R. CD44 and HCELL: preventing hematogenous metastasis at step 1. FEBS Lett (2011) 585:3148-58. doi:10.1016/j.febslet.2011.07.039

58. Sackstein R. Glycoengineering of HCELL, the human bone marrow homing receptor: sweetly programming cell migration. Ann Biomed Eng (2012) 40:766-76. doi:10.1007/s10439-011-0461-8

59. Mondal N, Stolfa G, Antonopoulos A, Zhu Y, Wang SS, Buffone A Jr, et al. Glycosphingolipids on human myeloid cells stabilize E-selectin-dependent rolling in the multistep leukocyte adhesion cascade. Arterioscler Thromb Vasc Biol (2016) 36:718-27. doi:10.1161/ATVBAHA.115.306748

60. Di Stasio E, De Cristofaro R. The effect of shear stress on protein conformation: physical forces operating on biochemical systems: the case of von Willebrand factor. Biophys Chem (2010) 153:1-8. doi:10.1016/j.bpc.2010.07.002

61. Rosenstein Y, Park JK, Hahn WC, Rosen FS, Bierer BE, Burakoff SJ. CD43, a molecule defective in Wiskott-Aldrich syndrome, binds ICAM-1. Nature (1991) 354:233-5. doi:10.1038/354233a0

62. Pace KE, Lee C, Stewart PL, Baum LG. Restricted receptor segregation into membrane microdomains occurs on human $\mathrm{T}$ cells during apoptosis induced by galectin-1. J Immunol (1999) 163:3801-11.

63. La M, Cao TV, Cerchiaro G, Chilton K, Hirabayashi J, Kasai K, et al. A novel biological activity for galectin-1: inhibition of leukocyte-endothelial cell interactions in experimental inflammation. Am J Pathol (2003) 163:1505-15. doi:10.1016/S0002-9440(10)63507-9 
64. Chang J, Patton JT, Sarkar A, Ernst B, Magnani JL, Frenette PS. GMI-1070, a novel pan-selectin antagonist, reverses acute vascular occlusions in sickle cell mice. Blood (2010) 116:1779-86. doi:10.1182/blood-2009-12-260513

65. Wun T, Styles L, Decastro L, Telen MJ, Kuypers F, Cheung A, et al. Phase 1 study of the E-selectin inhibitor GMI 1070 in patients with sickle cell anemia. PLoS One (2014) 9:e101301. doi:10.1371/journal.pone.0101301

66. Telen MJ, Wun T, Mccavit TL, De Castro LM, Krishnamurti L, Lanzkron S, et al. Randomized phase 2 study of GMI-1070 in SCD: reduction in time to resolution of vaso-occlusive events and decreased opioid use. Blood (2015) 125:2656-64. doi:10.1182/blood-2014-06-583351

67. Azab AK, Quang P, Azab F, Pitsillides C, Thompson B, Chonghaile T, et al. $\mathrm{P}$-selectin glycoprotein ligand regulates the interaction of multiple myeloma cells with the bone marrow microenvironment. Blood (2012) 119:1468-78. doi:10.1182/blood-2011-07-368050

68. Berg EL, Yoshino T, Rott LS, Robinson MK, Warnock RA, Kishimoto TK, et al. The cutaneous lymphocyte antigen is a skin lymphocyte homing receptor for the vascular lectin endothelial cell-leukocyte adhesion molecule 1. J Exp Med (1991) 174:1461-6. doi:10.1084/jem.174.6.1461

69. Friedrich M, Bock D, Philipp S, Ludwig N, Sabat R, Wolk K, et al. Pan-selectin antagonism improves psoriasis manifestation in mice and man. Arch Dermatol Res (2006) 297:345-51. doi:10.1007/s00403-005-0626-0

70. Mazo IB, Massberg S, Von Andrian UH. Hematopoietic stem and progenitor cell trafficking. Trends Immunol (2011) 32:493-503. doi:10.1016/j. it.2011.06.011

71. Ley K. The role of selectins in inflammation and disease. Trends Mol Med (2003) 9:263-8. doi:10.1016/S1471-4914(03)00071-6

72. Laman JD, Maassen CB, Schellekens MM, Visser L, Kap M, De Jong E, et al. Therapy with antibodies against CD40L (CD154) and CD44-variant isoforms reduces experimental autoimmune encephalomyelitis induced by a proteolipid protein peptide. Mult Scler (1998) 4:147-53. doi:10.1177/135245859800400312

73. Hutas G, Bajnok E, Gal I, Finnegan A, Glant TT, Mikecz K. CD44-specific antibody treatment and CD44 deficiency exert distinct effects on leukocyte recruitment in experimental arthritis. Blood (2008) 112:4999-5006. doi:10.1182/blood-2008-04-150383

74. Winkler IG, Barbier V, Nowlan B, Jacobsen RN, Forristal CE, Patton JT, et al. Vascular niche E-selectin regulates hematopoietic stem cell dormancy, self renewal and chemoresistance. Nat Med (2012) 18:1651-7. doi:10.1038/ nm.2969

75. Sackstein R, Fuhlbrigge R. The blot rolling assay: a method for identifying adhesion molecules mediating binding under shear conditions. Methods Mol Biol (2006) 341:217-26. doi:10.1385/1-59745-113-4:217

76. Sackstein R, Fuhlbrigge R. Western blot analysis of adhesive interactions under fluid shear conditions: the blot rolling assay. Methods Mol Biol (2009) 536:343-54. doi:10.1007/978-1-59745-542-8_36

Conflict of Interest Statement: The authors declare that the research was conducted in the absence of any commercial or financial relationships that could be construed as a potential conflict of interest.

Copyright (c) 2017 Ali, Abuelela and Merzaban. This is an open-access article distributed under the terms of the Creative Commons Attribution License (CC BY). The use, distribution or reproduction in other forums is permitted, provided the original author(s) or licensor are credited and that the original publication in this journal is cited, in accordance with accepted academic practice. No use, distribution or reproduction is permitted which does not comply with these terms. 